This is an electronic reprint of the original article. This reprint may differ from the original in pagination and typographic detail.

Author(s): Larkins, Cath; Kiili, Johanna; Palsanen, Kati

Title: A lattice of participation: reflecting on examples of children's and young people's collective engagement in influencing social welfare policies and practices

Year: $\quad 2014$

Version:

Please cite the original version:

Larkins, C., Kiili, J., \& Palsanen, K. (2014). A lattice of participation: reflecting on examples of children's and young people's collective engagement in influencing social welfare policies and practices. European Journal of Social Work, 17(5), 718736. https://doi.org/10.1080/13691457.2014.928269

All material supplied via JYX is protected by copyright and other intellectual property rights, and duplication or sale of all or part of any of the repository collections is not permitted, except that material may be duplicated by you for your research use or educational purposes in electronic or print form. You must obtain permission for any other use. Electronic or print copies may not be offered, whether for sale or otherwise to anyone who is not an authorised user. 
Käsikirjoitus, ei vielä julkinen

Cath Larkins, Johanna Kiili \& Kati Palsanen

\title{
A lattice of participation: reflecting on examples of children's and young people's collective engagement in influencing social welfare policies and practices.
}

(Accepted with minor revisions to European Journal of Social Work)

\begin{abstract}
The article introduces four case studies from Wales, France and Finland and explores the situated, intergenerational, and dynamic nature of collective participation in child welfare settings. Collective participation is conceived of as a process of engagement in which children and young people have some influence over the initiation or direction of a project; and as seeking a product, or outcome. The case studies represent a range of forms of collective engagement and highlight some key resources which supported children's participation (communicative spaces; time; money; knowledge; social position; attitudes; social networks; institutional commitment; equipment; food and transport). Challenges encountered in achieving effective participation in different nations within Europe are also identified, related to generation barriers and the distribution of resources. These elements are used to construct a lattice of participation: a model for conceptualising children and young people's collective engagement in participatory projects. The model provides a tool for visualising how, at different stages of a project, actors (children, young facilitators, adults and institutions) exercise influence by directing the use of different resources, such as finance and time. It invites reflection on why influence is limited in some stages of a participatory project, and how is supported in other stages.
\end{abstract}

Keywords: collective participation, child welfare, impact, children’s participation 
As social work is in the grip of neo-liberalism in the form of increasing privatisation, new managerialism and standardised assessments, 'social workers and service users together need to make an effective input' into defining service standards (Welbourne, 2011, p. 414). There is also 'great need to further investigate models for collective user participation in order to provide users with the power to influence service delivery’ (Seim and Slettebø, 2011, p. 497). User participation can however be consumerist (where an initiating agency gathers information from users and decides what to do with it) or democratic (seeking to redistribute power and support direct action to bring about change, rooted in people’s lives) (Beresford, 2002, p.97). This paper introduces four case studies of collective participation, which involved children and young people who had received support from social workers and were living or had lived in residential child welfare settings within Wales, France and Finland. We explore these case studies to identify the factors that enable and constrain young service users' influence and direct action. Embracing the messiness and contingencies of everyday political life and social relations which analyses of participation often wish away (Gallagher, 2008), we apply a situated, intergenerational, and dynamic perspective to exploring the processes of participation and the changes that are produced by these case studies. From this analysis we discuss elements of a lattice of participation: a model for conceptualising relational influence in and through collective participation that may be of relevance within and beyond residential child welfare settings.

\section{Children and young people's collective participation}

Definitions of young people's collective participation in Europe can be fairly fluid, 'situated on a continuum enabling on the one side the exercise of citizenship, on the other, the social integration of young people’ (Loncle, 2008, p. 37) The influential ladder of participation described rungs up which children may move from being informed to initiating, directing and sharing decision making (Hart, 1992 in Hart, 2008). This model should not however be used to argue that children must 
operate at the highest rungs, as they may not always wish or be able to (Hart, 2008); the possibility for influence is linked to openings, opportunities and obligations (Shier, 2001).

Collective participation can then be conceived of as a process of engagement in which children and young people have some influence over the initiation, direction or goal of a project. It also seeks a product, or outcome. This is implied in United Nations Convention on the Rights of the Child (UNCRC) Article 12 which states that children and young people have the right both for their views to be listened to; and, for these to be given due weight in relation to matters that affect them (UN, 1989). This has recently been reiterated in the Council of Europe recommendation on participation which calls for that member States to:

'ensure that providers of services to families and children support children and young people to participate in service development, delivery and evaluation’ ... identifying obstacles to their participation and ways of overcoming them' (Council of Europe 2012, p. 5)

This recognition of children's capacity and rights acts in some ways as a challenge to dominant conceptions of childhood as a time of incompetence and dependence. In our analysis children and young people are recognized as competent social actors, who live in relationships of social interdependence with adults (Cockburn, 2010). Childhood is conceptualized as an intergenerational category; emphasis is on the interaction between the children's generation and that of the adults', as well as the impact these two have on each other (Alanen, 2009). Citizenship is seen as a status associated with recognition and respect (Author’s Own 3).

Whilst there is a growing body of research on children and young people’s individual participation in child welfare settings where children contribute to making decisions about their own care plans (Pölkki, Vornanen, Pursiainen \& Riikonen, 2012; Vis, Holtan \& Thomas, 2012) there is relatively little focused on collective participation (Seim \& Slettebø, 2011) in which groups of children seek 
change in the practices or policy that affect them. Thomas and Percy-Smith (2011) suggest that formal collective participation initiatives for children in alternative care in England are more likely to lead to changes in young people themselves than in policy. Robin (2010) notes that although there are notable examples of peer-led initiatives involving older young people, collective participation opportunities in child protection in France are in their infancy. In Finland, collective participation structures are rare and underdeveloped which may be one reason why children in foster care have reported having only minor possibilities to influence matters concerning them and their lives (Pölkki et al., 2012).

A recurring tension in participatory work arises between the emphasis placed on influence within the participatory process, versus the influence that is produced from participation (Shier, 2010). The ‘messy, fraught and ambiguous’ (Gallagher, 2008, p. 404) process of children’s participation occurs through interdependent and intergenerational networks of connection between a variety of actors (Mannion, 2007; Bjerke, 2011) through which different aspects of influence and agency are enabled and constrained (Wyness, 2013). Analysing participation means exploring adults' roles as well as those of children (ibid).

The influence resulting from participation (its products) have been characterised as changes in services, policies and institutions, social and power relations, and in children's personal development and well-being (Kirby et al. 2004 in Crowley, forthcoming). But there is very little academic attention paid to assessing the conditions that enable such changes. When considering the effectiveness of children's participation in relation to schools and school councils, Tisdall (2010) used the work of Cornwall and Coelho (2007) who set out five requirements of participatory structures: recognition of people as citizens (not only clients or beneficiaries); critical consideration of representation and who has the legitimacy to speak for others; reflection on what participation means for different actors (not confining thinking to structures); acknowledgement that change needs committed bureaucrats, inclusive institutions and involvement of civil associations, and; 
attention to time as participation is situated in social, cultural and historical contexts. Recent international work confirms that where participatory work mainly concentrates on producing the sense of being listened to, impact on policy is limited (Crowley, forthcoming). Conversely, when aims are clear, efforts are focused on well-understood policy or practice opportunities, or local participation structures are linked to civil society groups, impacts on policy and services are more likely (ibid.).

\section{The Research Process}

The four case studies in this paper, from Wales, France and Finland, are drawn from our personal experiences. We were involved in these case studies in different paid positions (participation consultant, PhD researcher, social worker or senior officer) but we shared a common role (acting as facilitators seeking to support children and young people to create new forms of knowledge and change in systems). We considered these projects to be action research, although this was not always how they were defined by our employers and there are some tensions in this definition as initial aims were not identified by young people.

Using a symposium at the 2013 European Congress of Social Work Research we sought to move from these projects we saw as ‘second person’ towards third person’ action research (Reason \& Bradbury, 2003, p.159). Our third person research involved: building relationships; sharing reflections; and learning from these reflections to identify how influence operates. We selected six case studies related to social work to present at the symposium. Afterwards, we continued to analyse four of these which had common features: all related to children who had lived in residential child welfare settings and received interventions from social workers. Our process represents only multi-person not inter-community dialogue, but we followed common action

research modes (ibid, p. 170) combining action research forms to build capacity for collaboration, 
engage other people, work with issues that emerged in a way that aimed at improving actual understanding and future practice, thus enabling us to derive a new way of looking at things. Two young people and two adult facilitators from case study 3 commented on the draft paper and the emerging model and their suggestions were added.

Existing research on children's participation has identified the need to think relationally (Mannion, 2007; Wyness, 2013). Our relational analytical frame therefore draws on Alanen’s (2009) argument that exploring intergenerational relations requires consideration of the practices through which actors mobilise resources and the intersection of generation and other structures. We applied this to explore 13 stages (indicated in italics below) we identified in our cases through which actors (indicated in bold in case studies) used resources to exercise influence. Six stages form the participatory process: setting aims; involving others; identifying themes for inquiry; deciding methods; creating data and analysing information. These stages led to creating various outputs (such as reports and videos) that were used to try to produce impact through: action planning; sharing findings; lobbying; changing policy and guidance; changing training; and, changing practice. ${ }^{1}$ Rather than attempting to identify national differences from such a small number of projects that span 10 years, we use these case studies to develop a preliminary model for making relational sense of the challenges and successes participatory projects encounter. 


\section{Four messy case studies of participation}

\section{Case Study 1: An Audit of Participation in Social Services in Wales (CS1)}

A participation consultant (first author) initiated this research. After conducting an annual audit of a

local social services department's adherence to their children's participation strategy, in which no children were, the facilitator recommended that children and young people should lead future local audits. The local authority accepted this recommendation and in 2004 contracted two adult facilitators to carry out the next annual audit.

The facilitator and a young volunteer in a peer-led organisation, attended a local conference for children and young people living in residential child and invited all attendees to become young auditors. Eight young people (four males, four females; aged 12-16 years) decided to take part. They received training, which the head of children's services attended on one day to show his commitment to taking their recommendations seriously and implementing any recommendations that he could.

The participation strategy had five subthemes and the aim of assessing achievement of these was set by the local authority. Within these themes, however, the young auditors wrote questions, selected consultation methods (draw/write techniques) and identified groups to consult with.

Young auditors made suggestions about who to consult and data was collected through focus groups with 48 young service users (aged 6-22 years). Some focus groups were run by young auditors, supported by adult facilitators. The young auditors analysed the data, wrote recommendations and created a road map identifying a pathway by which the local authority could progress towards these. Due to time constraints, adult facilitators wrote a full report, and a summary report for young people involved in the focus groups (which young auditors approved). 
The young auditors presented their findings and recommendations to a senior management team meeting and the Children's Commissioner. Some recommendations were acted upon by the local authority (Author's Own 1). A website and a permanent forum for children in care were established (and continue to exist in 2014). In 2005 the facilitator was commissioned to work to develop clearer written information about social work assessments and some Auditors were involved in this project. The social work training and practice manual was also changed to include some specific standards that young people had suggested. However, without explanation, some recommendations such as 'Social workers should do what they say they will do' were not written into the practice manual.

\section{Case Study 2: Action Research in France (CS2)}

A PhD researcher (first author) initiated this project as part of her PhD research, in which she aimed to act as an adult facilitator, supporting six groups of children to identify and take action on issues that concerned them. The $\mathrm{PhD}$ research also considered the links between these action research projects, EU policy and citizenship theory (Author’s Own 2 and 3).

The adult facilitator sought participation from services working with children who experienced (according to EU definitions) particular difficultly in accessing their rights. Six projects were initiated in 2008-2009. CS2 focuses on one of these in France where a children's research group (2 male, 5 female; aged 5-13 years) was set up in in a children's home. All children using each service were invited to take part in the action research, Child Researchers opted in and out of the research activities at any point.

Within the aims, child researchers set specific themes to consider. They used a selection of games aimed at prompting discussion, art materials, video and still cameras and printing facilities to create

data, then asked for more resources to create new methods and the facilitator provided these. They 
reviewed their data and at subsequent meeting chose what areas to explore further. . Each session was attended by one facilitator, but some activities took place in other rooms where the facilitator was not present. In the final sessions, the group members planned further actions to be undertaken with their support workers. They dictated a short report, written up by the adult facilitator then checked and amended by the group.

They presented their report and video to their children's home staff. They wanted more engagement from staff in organised play, to go home more often and to have less shouting in meetings. At a follow up visit more organised play was reported but there were no accounts of changes outside of the institution, such as with meetings or visits home. The home manager agreed to consider how meetings could be improved but the children did not want their video to be shown publicly and the facilitator lacked connections to help progress their other demands further.

\section{Case Study 3: Child welfare tour and forums in Finland (CS3)}

The Ombudsman for Children in Finland initiated the child welfare tour to draw public attention to the experiences of young people in care and conduct national policy lobbying. The 2011 tour was planned and realized by 10 young experts from Pesäpuu (NGO) together with adult facilitators from the offices of the Ombudsman (including the second author), the National Institute for Health and Welfare, the Central Union for Child Welfare (NGO) and Pesäpuu. The young experts (5 male, 5 female; aged 16-25) have experience of alternative care and they are called 'Survivors'. The group was established six years ago and it aims, among other things, to improve child welfare services. They have been an advisory group for the Ombudsman since 2008.

120 Young participants (around 60 male, 60 female; aged 12-20 years) were invited by their social workers or other local officials to participate in forums in six locations across Finland. They decided whether or not to attend and could opt out of any activity during the event. 
Within the broad aims, Survivors and adult facilitators decided that discussion of the rights of children in care be put on the tour-agenda. Between 2-4 Survivors led each four-hour forum while 3-4 adult facilitators acted as background supporters. Working methods included introductory exercises, group work and round-discussions.

During the forums Survivors and adult facilitators collected data on a laptop. All participants could check what was written down. This information was analysed and a plan of action was determined by the young and adult facilitators together with the Ombudsman. The findings were written by one of the Survivors with the help of adults. The report was disseminated to authorities and young participants. The report includes a development programme and proposals for the enhancement of services, aimed at the policy-makers and professionals. (Author’s Own 3).

Survivors, adult facilitators and the Ombudsman lobbied through seminars and meetings organized by national or local authorities. The report is used as teaching material in polytechnics and universities and also informs a working group, set up by the Minister of Health and Social Services in 2012.

\section{Case Study 4: The young developers - a method to increase participation in Finland (CS4)}

This idea came from social workers who wanted to develop child welfare services together with young people in care. Social workers (including the third author) formed a young developers group, deciding to recruit young people who have no acute difficulties, such as severe mental health problems. The Developers (involving in the past two years five males, ten female; aged 15-20 years) meet every two weeks, with two to three social workers (adult facilitators) present.

Within the broad aim, specific themes of work were decided together with Developers and adult 
facilitators. These include, the services child welfare should provide, developing cooperation between schools and child welfare services, and positive encounters between young people and child welfare professionals.

Adult facilitators initially decided working methods (small group discussions, cards and photos) then Developers selected from these. Adult facilitators made notes of discussions and analysed this data and develop these findings into presentations and videos with the Developers. Over time, adult facilitators continued to organise the group framework (including resources and use of working time) but group activities were designed together with the Developers. Plans of actions were determined together. For each of the selected themes, the Developers and adult facilitators work together to figure out how and for whom the findings should be delivered. The Developers found it important to deliver their material directly to decision-makers and professionals. Three Developers also took part in a child welfare tour forum (CS3) and have since co-operated with the Survivors.

Lobbying is undertaken by Developers and adult facilitators. The Developers decide who and what they want to influence. Among other things they take part in the training of social workers at different professional development and training events and they regularly contribute to training of future social workers at the University of Helsinki. Based on the Developers' recommendations family group conferences are increasingly used as a working method in Helsinki child welfare services. Furthermore the City of Helsinki has made a policy recommendation that the child welfare professionals in every residential area should develop services together with the serviceusers. The manager responsible of child welfare has decided that, together with the Developers, plans for distributing and embedding the Developer-model will be made this year. 


\section{Findings}

As we analysed these case studies we identified certain recurrent resources: communicative spaces; worker and young people’s time; money; knowledge of children's experiences; social position or credibility; professional/technical knowledge; facilitators attitudes; social networks (of young people and workers); equipment (computers, laptops, stationery, musical instruments); food and transport. Institutional commitment, a political climate of support and understanding of the benefits of participation were also significant. Constraints arose where children and young people did not have access to these resources, which sometimes reflected their generational social position.

Confirming that participation is messy (Gallagher, 2008), fluid (Horwath, Kalyva, \& Spyru, 2012) and relational (Mannion, 2007) these case studies also revealed how resources could be mobilised by different actors (young people in core groups - Auditors, Child Researchers, Survivors and Developers; other young participants; adult facilitators; other workers; managers and decision makers; and ombudsmen) through practices such as suggesting, deciding and dialogue. Dialogue was a circular process through which different actors suggested, responded, decided and then acted in accordance with shared decisions. Resources could belong to different entities (individual actors, the participatory project, or external bodies).

There were similarities and differences in how resources were used to enable influence in each of the 13 stages we identified in the action research projects. For example, in the creating outputs stage, all young people in the core groups decided the use of project resources in dialogue with the adult facilitators. However, in changing training, core groups undertook different actions. Young Auditors (CS1) made suggestions to managers; Child Researchers (CS2) simply allowed their data to be used for training; Survivors (CS3) used project resources (their own and workers' time) to apply social pressure by lobbying to get their findings added to guidance; and, Developers (CS4) 
used project resources and the external communicative spaces of University of Helsinki class rooms, to deliver teaching themselves.

Influence appeared to be constrained when local practices (by funders, host organisation and facilitators) obstructed access to and use of resource. Sometimes these practices were underpinned by structures related to generation, employment status and relationship to financial decision making. Some of these same factors also affected the extent to which participation facilitators could exert influence. These findings are explore below in relation to four of the 13 themes: setting aims, identifying themes, sharing findings, and changing practice. We conclude this section by drawing together a model for exploring influence within and between participatory projects.

\section{Setting aims}

Children and young people were not involved in setting initial aims for three of these projects. The Auditors (CS1) and Developers (CS4) were initiatives suggested by facilitators or social workers who tried to mobilise political climates favourable to children’s participation to enable resources to be directed towards these particular projects. In these situations, confidence in the facilitators built through work relationships was key, as was political climate of support for children’s participation generated by national government and NGOs. In the child researcher project (CS2) aims were set by the facilitator who controlled the $(\mathrm{PhD})$ time and money resources that were used in the project. In all three of these cases then, adults had social positions in paid work/study environments, which gave them relative control over project resources and access to communicative spaces in which to exert social pressure, mobilising political will in communicative spaces to influence the use of external resources. However, as illustrated (Figure 1), in CS3 Survivors made suggestions about the initial aims of the child welfare tour which were then implemented. As childhood is a social position broadly associated with limited access to resource holding, social esteem and social support 
for participation, the predominant exclusions of children and young people from these initial decisions reconfirms their generational position (Alanen, 2009; Wyness 2013.) CS3 shows that local practices can overcome this constraint.

Figure 1: Core group and adult facilitators’ influence in setting aims.

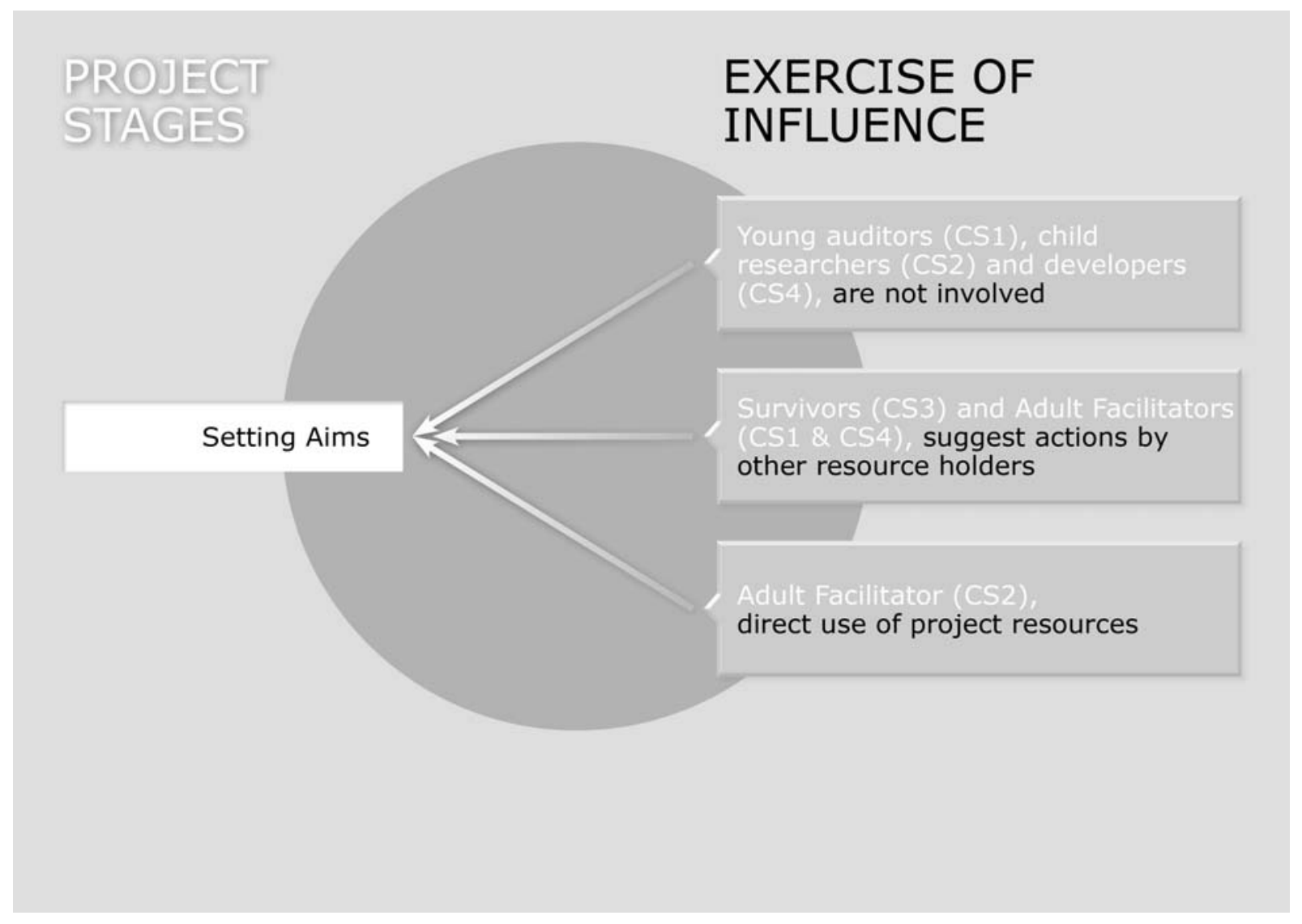

\section{Identifying themes}

The young auditors (CS1) were given a set audit framework to follow; this same constraint had been imposed on the adult facilitator in the previous year. As shown in figure 2, in the other three case studies, children and young people influenced what themes should be explored within the limits of the projects' resources. For example, the Survivors (CS3) discussed with the adult 
facilitators which themes should be presented to other young people who would participate in the tour. With both the Survivors (CS3) and the developers (CS4) decisions were made through dialogue and this enabled them to exercise influence about the use of the project' time and space and knowledge generated from their own experiences and suggestions by adult facilitators. The child researchers (CS2), in contrast, decided what themes to explore using the project resources, without dialogue with the adult. In these three case (CS2, CS3 and CS4) adult facilitators took a step back and trusted children and young people's competence to influence the use of the resources secured for the project. However, in all four cases, both young people’s and adult facilitators' influence over themes was constrained by the project aims and the extent of resources allocated to the project. However, where projects had a core group and second tier of participants (as in CS1 and CS3) a second type of young actor were also excluded from influences over identifying themes; the young participants who the Young Auditors and Survivors consulted with were given set themes. 
Figure 2: Core group, young participant and adult influence in identifying themes.

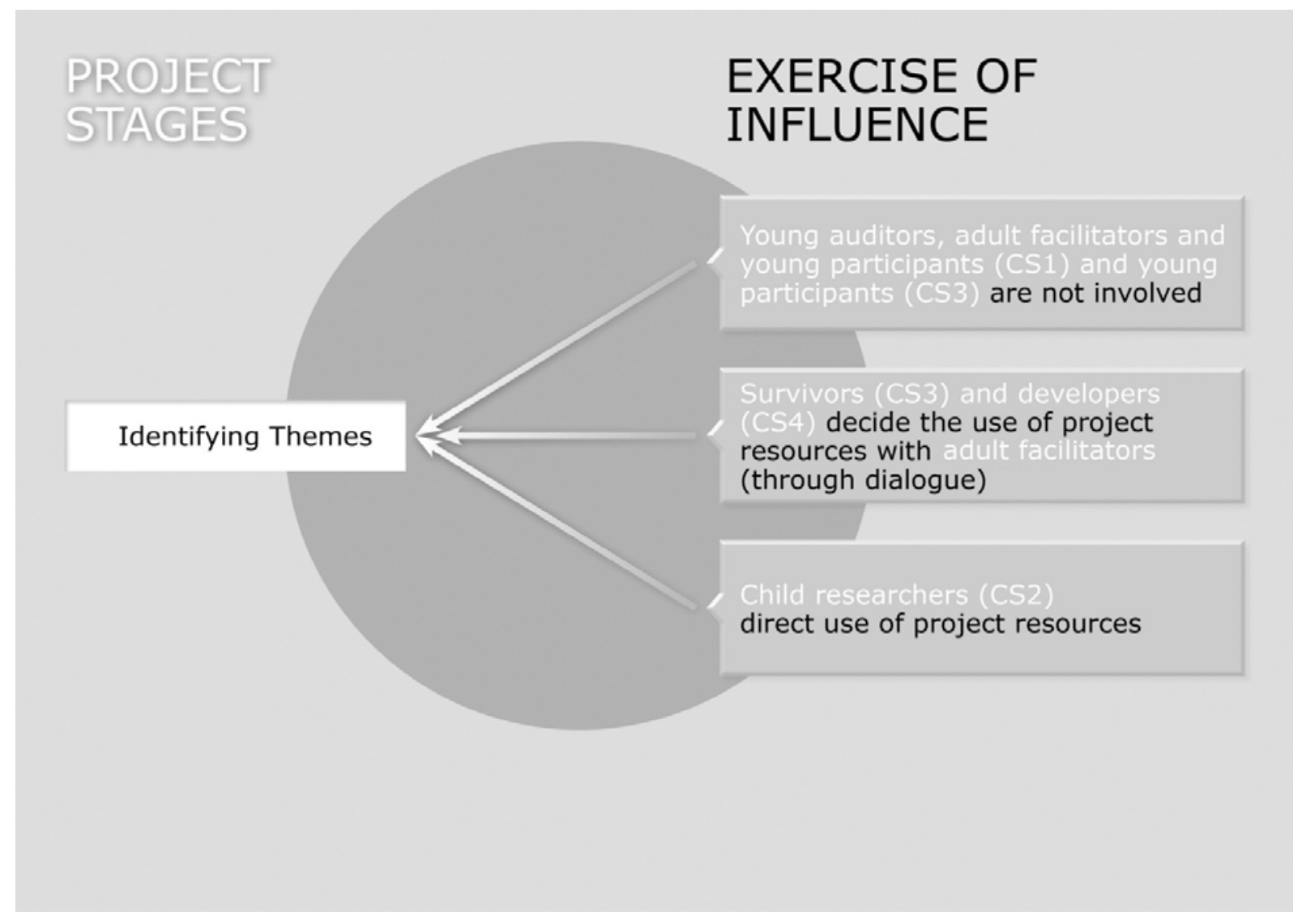

\section{Sharing findings}

In all four case studies, the core children and young people had some influence over which findings were shared, where and how. In three cases (CS1, CS3 and CS4) young people in dialogue with suggestions from adult facilitators made decisions about how to the project resources (the findings they had created, money, young people's and workers' time, transport, social networks and social positions/credibility). Young people used these resources to gain access to communicative spaces with adult resources, and presented their outputs directly to decision makers, challenging assumptions about young people's competence in formal communicative spaces, and building understanding that participation could be effective and lead to improved services. Generational constraints and limitations in personal experiences were challenged through the participatory 
projects, as young people who had not had access to these spaces at the start of the project were then mobilising these resources to support their influence. These case studies also challenged existing norms through sharing findings using stories, pictures and music, with the aim of achieving greater emotional engagement from those who had the power to bring about changes. Whilst it is not known whether these strategies led to goals for change being achieved, seeking emotional engagement from people you are seeking to influence is a recommended strategy for change within social work (Bilson \& Thorpe, 2007).

In the other case (CS2), the child researchers decision to use their findings and other project resources to apply social pressure for change changed before it was enacted. They overturned their decision to share their video with others outside of the children's home, as some children became uncomfortable with this proposal. Each individual therefore took a copy of themselves on video which they could choose to share or not share. On figure 3, this change is shown by the black cross and line. Through this processes they consequently directed the use of one project resource (their video), turning it from collective into personal property. They also directed use of their written report, deciding who it should be given to. This is shown by the lower white line. 
Figure 3: Core group influence in sharing findings

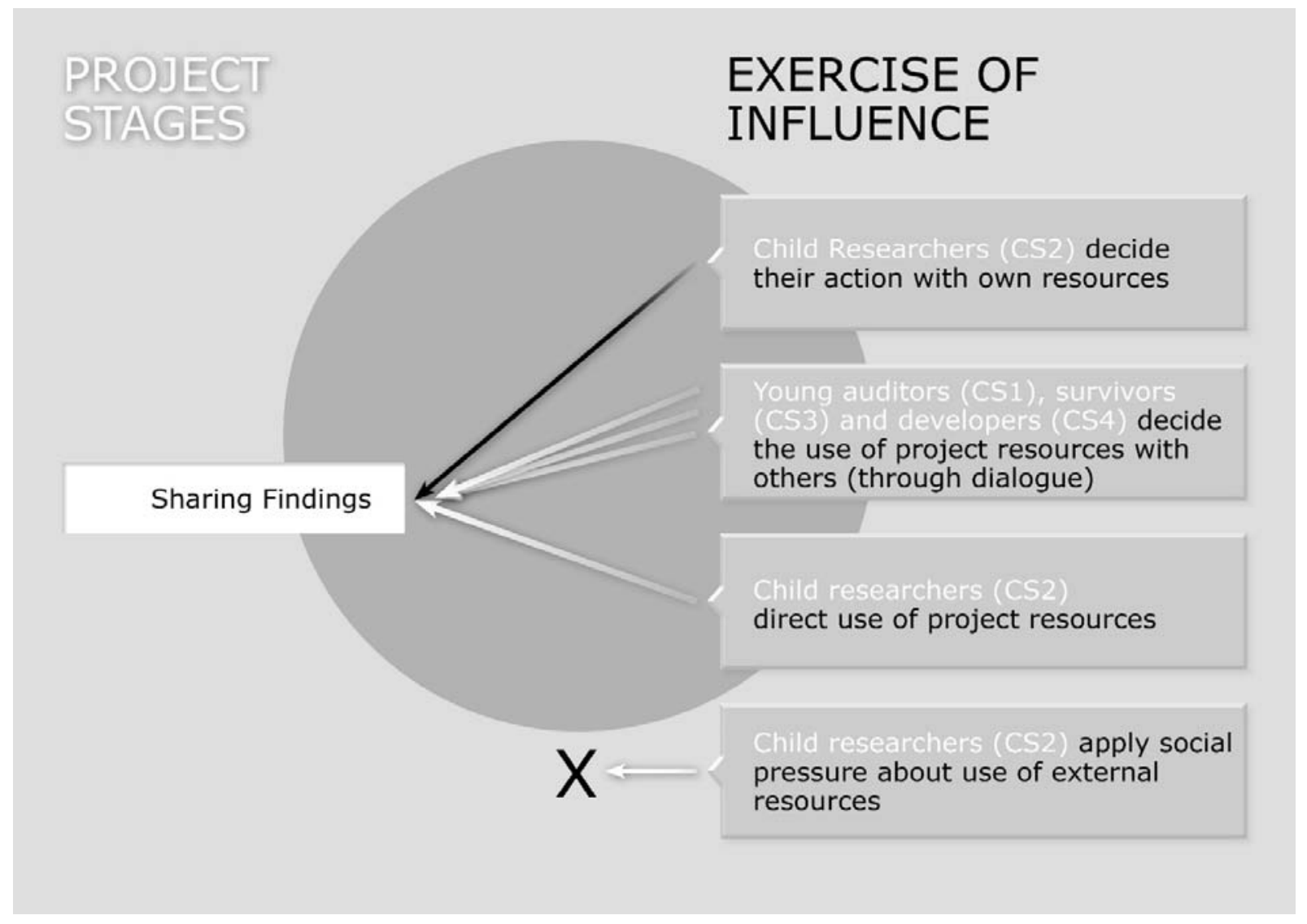

\section{Changing Practice}

The Auditors (CS1) suggested establishing a children in care forum and providing better information. These recommendations were taken up immediately by local authority decision makers who controlled the use of financial resources. They employed someone to set up and run a forum and contracted a facilitator to develop young person friendly information. This occurred at a time when participation was receiving strong political support across Wales. Echoing Crowley (forthcoming), in CS1 change appeared to be facilitated because the facilitator had knowledge of live policy contexts, which enhanced institutional commitment. CS1 was not a consultation event. Rather, facilitators sought to establish links with policy opportunities after the findings had been written. In this way adult facilitators tried to mobilise external resources to apply social pressure 
towards achieving the agenda for change which young people had set. Other recommendations unlinked to current policy, such as a practice standard stating Social Workers must do what they have said they will do, were still pursued by the Auditors and facilitator but not implemented.

Policy links were not always important however. Recalling Alanen’s (2009) point that the structural contexts of children's lives are recreated and challenged through everyday practices of local actors, the Developers (CS4), together with adult facilitators used a focus on local practices and the institutional commitment of municipal social services to produce changes in practice. The management commitment to involve Developers in planning future service user participation initiatives is expected to result in Developers deciding the use of future external resources, in dialogue with adult decision makers.

In every case study, at least one goal for change in practice that children and young people identified was not achieved. For example, the Child Researchers (CS2) achieved their aims of more play by making suggestions about the actions of their children home staff, but they did not achieve influence outside of the children’s home regarding how meetings were run. It was striking here that, like the child researchers, the adult facilitator was not in a paid work position which gave her access to child welfare communicative spaces outside of the children's home and she lacked relevant social networks. In other case studies, limits on the availability of external resources also appeared to in constrain the implementation of suggestions, or the range of joint decisions that could be made. 
Figure 4: Core group influence in changing practice

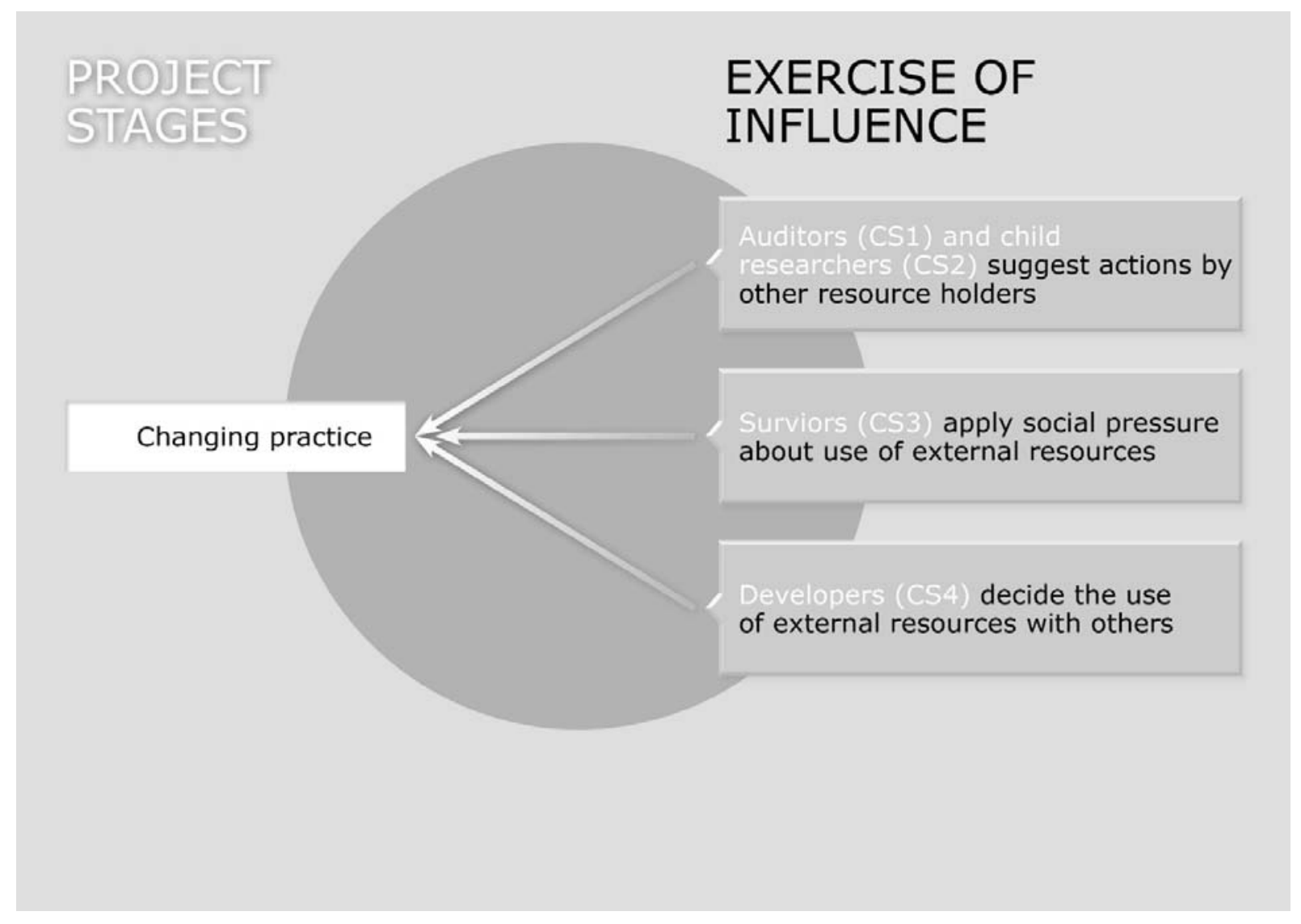

\section{A lattice of participation}

In the relational understanding of influence in participatory processes we have outlined, power is exercised through dynamic processes in which resources are mobilised. Children's and adults' access to opportunities to exercise relational influence is structured; their generational position or their relationship to resources in the world of paid work can limit their access to and decision making about some of resources involved in delivering participatory projects and child welfare services. Confirming Alanen's (2009) argument that constraints can be challenged through local practices, we observed that some children and young people were able to exercise influence through making suggestions and decisions about the use of resources, and dialoguing about or using 
resources themselves. Some also applied social pressure about the use of resources by others, when they were engaged in a participatory project that lasted over time (such as CS3 and CS4).

Across the project stages explored we identified the following ways in which actors exercise influence through mobilising resources (which might be their own, allocated to a project they are part of or external): Actors may:

- decide their action with own resources

- $\quad$ suggest actions by other resource holders

- $\quad$ decide the use of project resources with others (through dialogue)

- $\quad$ direct use of project resources (which may involve using these themselves)

- apply social pressure about use of external resources

- decide the use of external resources with others

Like Hart's (2008) critique of the participation ladder, these alternatives for exercising influence are options, rather than prescriptive. Within any project stage children may try to exercise influence through one or more approaches at a time (see Figure 2). If they meet (internal or external) barriers with their first attempt, they may initiate or be supported to exercise influence through a different form of action.

When the actions with resources of a given group of actors are mapped onto project stages, a pattern resembling a lattice appears (Figure 5). More dynamic than a ladder, this conceptualization depicts how similar or contrasting relational influence and constraint might be observed in different stages of collective participation. 
Figure 5: Lattice of core group influence in case study 2

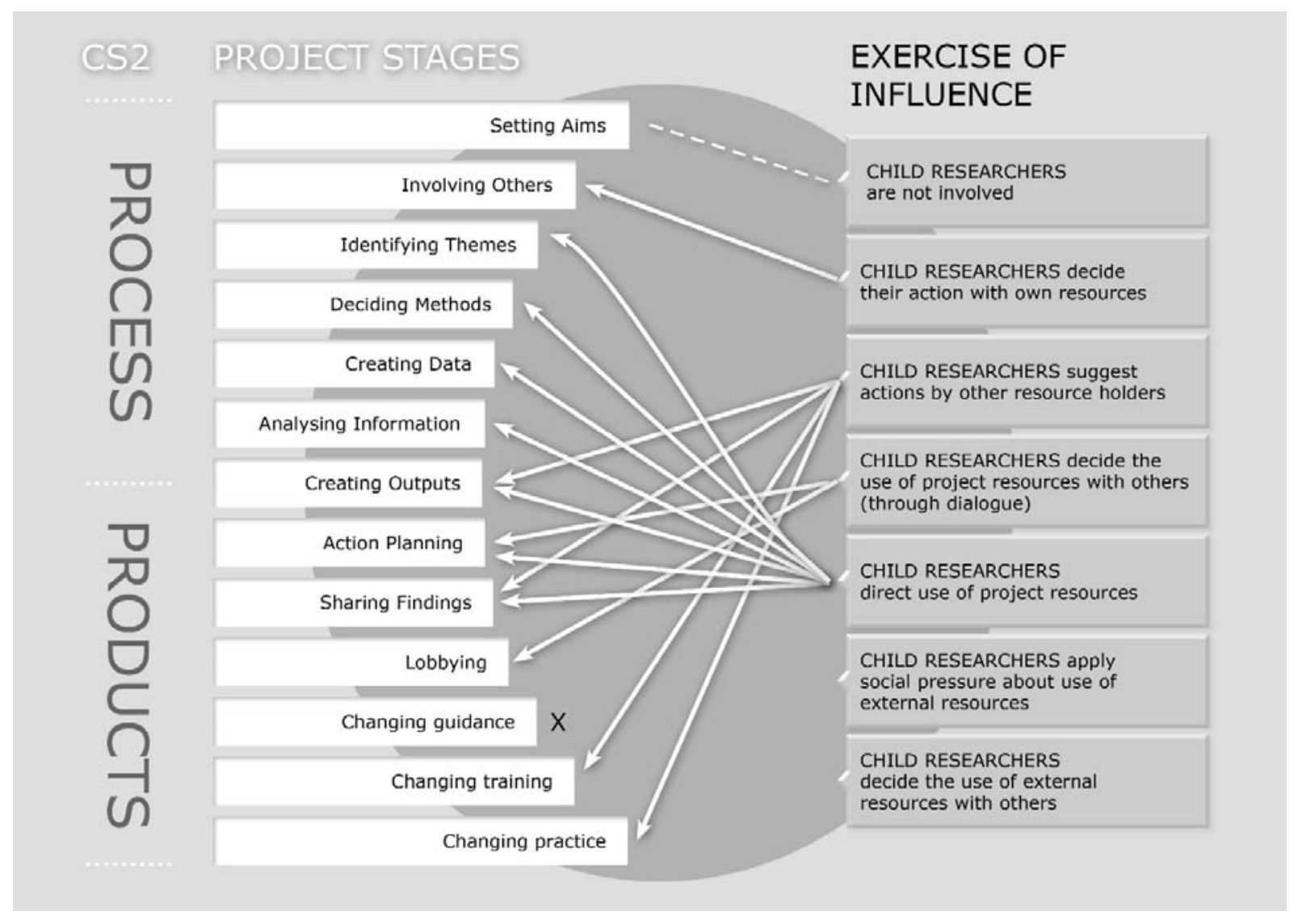

In different contexts children's influence appears in different stages in relation to their own resources, project resources and sometimes external resources of other projects or services. Influence is then being achieved through communication, but also through children and young people themselves acting with resources. The lattices were distinct for the different projects we considered (Figure 6). 
Figure 6: A lattice of participation for each case study
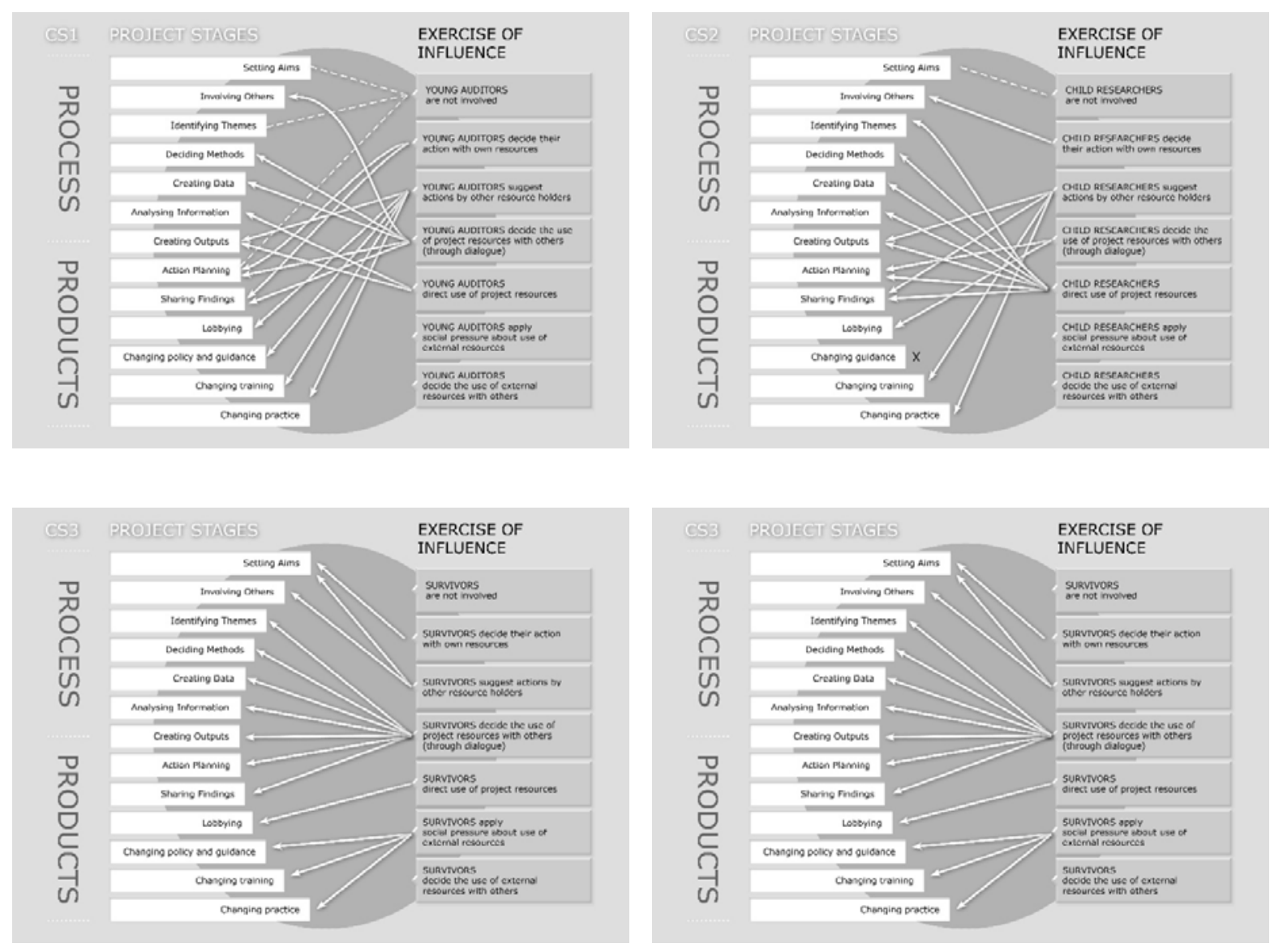

Whilst this article is not comparative, the similarities and differences between these case studies are striking. Those in Finland (CS3 and CS4) show a significant concentration around the process of dialogue with both projects also enabling young people to exercise social pressure over the use of external resources. In contrast, those in Wales and France (CS1 and CS2) are messier and show a criss-crossing pattern in which young people achieve direction over some project resources at fairly early stages of the participatory project, particularly in CS2 where they are taking direct action with resources themselves as soon as they are involved. In CS1 and CS2, young people are never successful in exerting social pressure themselves. This is partly because the projects were very time limited (3-6 months). Nonetheless, CS1 and CS2 did achieve some limited changes in local 
practices. All four of these case studies then show elements of democratic user involvement (Beresford, 2002). With the exception of CS3, they all also show elements of a consumerist approach (ibid.), as only in this instance were these young people able to set projects aims; in most cases they were following an agenda that had been set for them by a facilitator or service provider.

\section{Discussion}

Debating the content of a lattice of participation, by blowing apart participatory projects to reveal the dynamic, relational and (sometimes) messy ways in which actors try to achieve influence, appears to be a useful strategy for understanding the ways in which participation operates. It can reveal similarities and differences between the experiences of different actors. It can also help conceptualise how differences in the exercise of influence relate to actors relationships to resources.

The model may also support young and adult facilitators to consider how to move beyond young service users' collective participation meaning 'having a say’ or children making choices only about their own personal resources (such as time and opinions). It prompts consideration of how to enhance opportunities for children and young people to influence the use of project or external resources, and how to remove structural and practice-based obstructions to these possibilities.

Opportunities for influence, in two cases studies (CS3 and CS4), were supported by on-going communicative spaces and relationships that valued principles of participation. This confirms Sinclair's (2004) observation that embedding projects in rolling processes of participatory opportunities (as opposed to one-off events), can build sustained relationships and institutional commitment. However, it remains important to avoid all participatory projects becoming static and standing participatory bodies (Cockburn, 2010), as these may concentrate resources in the hands of a core group to the exclusion of other children. This applies to all our case studies; only a relatively 
few children and young people had access to time, space and connections to decision makers. In welfare settings, the question of which children and young people participate and whether they can represent the interests and experiences of others is central, as the tendency can be to engage only those who are older, compliant or have transport to attend long-term activities (Seim \& Slettebø, 2011). In these case studies, children involved in two (CS1 and CS2) were substantially younger than those involved in the others (CS3 and CS4). Transport difficulties were overcome by provision of taxis (CS1) or conducting collective participation in residential settings (CS2), indicating how appropriate assistance and resources can enable collective participation of all children (see also Authors own 2 \& 7). Representation must, then, be considered critically by asking who has legitimacy to speak for others (Cornwall \& Coelho, 2007); and, what resources are needed to enable all to speak and act for themselves?

Knowledge of policy contexts and networks established through engagement in paid employment were key resources mobilised by adult facilitators. However, decision-makers tend to have greater knowledge and confidence about policy opportunities, budgetary and contextual constraints than most children and many adult facilitators. Supporting children, young people and facilitators to access such knowledge and networks could widen the resources that participation projects have available. Drawing on this, their recommendations might then make stronger arguments engaged with structural conditions or identify ways that constraints may be challenged through local practices.

In our case studies, policy and institutional context were not only external resources; they also translate as practices within the relational spaces of everyday life. In relational spaces of their everyday lives, children exert influence through their direct use and creation of resources, not just through asking others to use resources for them. For example, Child Researchers (CS2) created information resources from their own ideas and used these to create persuasive arguments. They presented these to workers who changed their practice without a change in policy. When 
participation is to have a product which is external change, this confirms Mannion's (2007) and Gallagher's (2008) argument for moving away from participation primarily focused on influencing governments and concentrating instead on local contexts with their social, cultural and historical aspects (Cornwall \& Coelho, 2007). In other instances, products sought may be changes in policy, guidance or distribution of resources; this may require a national focus. As changes can only be achieved within a culture which respects children as competent citizens (Cornwall \& Coelho, 2007; Tisdall 2010), such a culture needs to become embedded in the practices and attitudes of national and local resources holders. An active commitment to overcoming structural barriers (generation and social positions in paid employment) is necessary.

To enable children and young people to exercise influence it is therefore necessary to consider the following:

- With which children should current resource holder share resources, to enable them to initiate participatory projects?

- What support do (these) children and young people need, and how can their influence in each of the project-stages be encouraged? Who are the potential allies to engage in these processes, to harness their support for the changes sought?

- How can formal and informal, physical and virtual communicative spaces and relationships be developed?

- What are the structural constraints and how might they be challenged?

- How can these changes be embedded in on-going cultures and participatory processes over time?

Asking these questions provides understanding of the significant resources and opportunities to debate what limitations are appropriate for what reason. It also enables consideration of the 
different resources and constraints that apply to participation facilitators as well as service providers, and how individual practice might enable young people and the workers who support them to experience greater influence in defining and creating effective social work practice.

\section{Conclusion}

Generational relationships to resources and social esteem can be disrupted through localised practices, enabling children to exercise influence in the sorts of spaces and over the sorts of resources from which they are normally excluded. This requires first changes in attitudes regarding the status of children and support for their participation in making and enacting decisions that influence how resources are used. Second, it requires reflection on processes and products of participation by asking how to ensure representation of the diversity of children's and young people's knowledge and whether this is inclusive of those who are the most marginalised. Through this transfer of resources and recognition steps towards children's representation in and influence on planning and delivery of child welfare services can be achieved.

Representing the challenges and strategies of participatory exchanges as a lattice provides a tool for reflecting on how the influence of all actors and institutions are subject to some social constraints and limited choices. Further research is needed to develop this initial framework in partnership with children and young people. Longitudinal assessment of the policy outcomes achieved through participation remains of utmost importance. 


\section{Acknowledgement}

The authors would like to thank all the children and young people who took part in the projects described in these case studies, and the other adults who supported their participation. We are grateful to participants in the symposium on this theme at the 2013 European Congress of Social Work Research and to the Survivors and adult facilitators who commented the draft. Special thanks to Väinö Teittinen for assistance with graphic design and to the anonymous reviewers for their insightful comments on an earlier draft of this paper.

\section{Notes}

${ }^{1}$ We have not here analysed products such as participants' enjoyment, self-esteem or skills, although these are valuable dimensions of change. Our focus on teaching probably reflects the social position of the adult facilitators, all of whom now have links with universities.

\section{References}

Alanen, L. (2009) Generational order. In Qvortrup, Jens \& Corsaro, William A. \& Honig, MichaelSebastian (eds) Handbook in Childhood Studies . Houndsmill, Basingstoke: Palgrave Macmillan, pp. 159-174.

Beresford, P, (2002), User Involvement In Research And Evaluation: Liberation or regulation?, Social Policy And Society, 1(2), pp93-103

Bilson, A. \& Thorpe, D. (2007) Towards aesthetic seduction using emotional engagement and stories Kybernetes 36 (7/8) pp. 936-945 
Bjerke, H. (2011) 'It’s the way they do it', Expressions of agency in child-adult relations at home and at school. Children and Society 25(2): 93-103.

Cockburn, T. (2010) Children and deliberative democracy in England. In: Percy-Smith B and Thomas N (Eds.), A Handbook of Children and Young People’s Participation . London: Routledge, pp 306-317

Cornwall A. \& Coelho V.S. (2007) Spaces for Change? The Politics of Citizen Participation in New Democratic Arenas. In Cornwall \& Coelho (eds) Spaces for Change? The Politics of Citizen Participation in New Democratic Arenas . Zed Books: London.

Crowley. A. (forthcoming) 'Evaluating the impact of children’ participation in public decisionmaking' in Author's Own (Forthcoming)

Council of Europe (2012) Recommendation CM/Rec(2012)2 of the Committee of Ministers to member States on the participation of children and young people under the age of 18

Gallagher, M. (2008) Foucault, power and participation. International Journal of Children's Rights, 16 (3) pp. 395-406. 
Hart, R. (2008) Stepping Back from 'The Ladder’: Reflections on a Model of Participatory Work with Children. In Reid, A., Jensen, B.B.,; Nikel, J., \& Simovska, V. (Eds.) Participation and Learning , Springer, pp 19-31.

Horwath, J., Kalyva, E. \& Spyru, S. (2012) “I want my experiences to make a difference” promoting participation in policy-making and service development by young people who have experienced violence Children and Youth Services Review 34(1), pp. 155-162.

Loncle, P. (2008) Pourquoi faire participer les jeunes? Expériences locales en europe, Harmattan, Paris.

Mannion G. (2007) Going Spatial, Going Relational: Why “listening to children” and children's participation needs reframing. Discourse: Studies in the Cultural Politics of Education , 28 (3), pp. 405-420.

Pölkki P., Vornanen R., Pursiainen M. \& Riikonen M. (2012) Children's Participation in Childprotection Processes as Experienced by Foster Children and Social Workers. Child Care in Practice 18 (2), pp. 107-125.

Reason H. \& Bradbury, P. (2003) Action Research: An Opportunity for Revitalizing Research Purpose and Practices. Qualitative Social Work 2(2): 155-175 
Robin, P. (2010) Echo du debat Francais sur les droits de l'enfant in Liebel, M. (2010) Enfants, droits et citoyenneté Hamattan, Paris.

Seim S. \& Slettebø T. (2011) Collective participation in child protection services: partnership or tokenism? European Journal of Social Work 14(4), pp. 497-512

Shier, H. (2001) 'Pathways to Participation: Openings, Opportunities and Obligations’. Children \& Society , 15(2) pp. 107-117

Shier, H. (2010) Children as Public Actors: Navigating the Tensions‘. Children \& Society , 24 (1), pp. 24-37

Sinclair, R. (2004) Participation in practice: making it meaningful, effective and sustainable. Children \& Society 18 (2), pp. 106-118.

Tisdall E.K.M. (2010) Governance and participation. In: Percy-Smith B and Thomas N (Eds.), A Handbook of Children and Young People’s Participation. London: Routledge, pp. 318-329.

Thomas, N. \& Percy-Smith, B. (2011) It’s about changing services and building relationships: evaluating the development of Children in Care councils. Child and Family Social Work, 17 (4), pp. 487-496. 
UN (1989) United Nations Convention on the Rights of the Child. Committee on the Rights of the Child. http://www.ohchr.org/en/professionalinterest/pages/crc.aspx

UN (2011) Committee on the Rights of the Child. State Reports and Concluding Observations. http://www2.ohchr.org/english/bodies/crc/crcs57.htm

Vis, S.A., Holtan, A. \& Thomas, N. (2012) Obstacles for child participation in care and protection cases—why Norwegian social workers find it difficult. Child Abuse Review 21 (1), pp. 7-23.

Welbourne, P. (2011) Twenty-first century social work: the influence of political context on public service provision in social work education and service delivery, European Journal of Social Work 14 (3) pp. 403-420.

Wyness, M. (2013) Children's participation and intergenerational dialogue: Bringing adults back into the analysis. Childhood 20(4), 429-442.

Author's Own 1

Authors' Own 2

Authors' Own 3

Authors' Own 4

Author's Own 5 
Author's Own 6

Author's Own 7

\section{Figure captions}

Figure 1. Core group and adult facilitators’ influence in setting aims.

Figure 2. Core group, young participant and adult influence in identifying themes.

Figure 3. Core group influence in sharing findings.

Figure 4. Core group influence in changing practice.

Figure 5. Lattice of core group influence in case study 2.

Figure 6. A lattice of participation for each case study. 